\title{
Leveduras vivas (Sacharomyces cerevisie) sobre o desempenho de novilhos terminados em confinamento e as características da carne e da carcaça
}

\author{
Effect of live yeast (Saccharomyces cerevisie) supplement on the performance, \\ meat and carcass characteristics of steers finished in feedlot system
}

Mikael Neumann $n^{[a]}$, Marlon Richard Hilário da Silva ${ }^{[b]}$, Danúbia Nogueira Figueira ${ }^{[c]}$, Cecília Aparecida Spada ${ }^{[c]}$,Luan Lucas Reinehricl, Mailson Poczynek ${ }^{[c]}$

[a] Engenheiro-agrônomo, doutor em Zootecnia pela Universidade Federal do Rio Grande do Sul (UFRS), pesquisador do Núcleo de Produção Animal (Nupran), professor do Curso de Medicina Veterinária da Universidade Estadual do CentroOeste (Unicentro), Guarapuava, PR - Brasil, e-mail: mikaelneumann@hotmail.com

[b] Médico-veterinário, mestre em Produção animal e Pastagens, professor do Curso de Medicina Veterinária da Universidade Estadual do Centro-Oeste (Unicentro), Guarapuava, PR - Brasil, e-mail: marlon_rhs@hotmail.com

[c] Médicos-veterinários do Núcleo de Produção Animal da Universidade Estadual do Centro-Oeste (Nupran/ Unicentro), Guarapuava, PR - Brasil, e-mail: mikaelneumann@hotmail.com

\section{Resumo}

O objetivo do estudo foi avaliar o desempenho e as características da carne e da carcaça de novilhos não castrados terminados em confinamento com dieta composta de silagem de milho e concentrado com e sem inclusão de Sacharomyces cerevisie. 0 confinamento teve duração de 210 dias. Foram utilizados 36 novilhos, destes 18 eram animais Canchim (5/8 Charolês, 3/8 Nelore) e 18 eram animais Brangus (1/2 Angus, 1/2 Canchim), com idade média de 8 meses, peso vivo médio inicial de $250 \mathrm{~kg}$. 0 delineamento experimental foi o inteiramente casualizado, composto por dois tratamentos com seis repetições, em baias com três animais. Não foram constatados efeitos positivos da inclusão de leveduras vivas secas sobre o consumo de matéria seca e sobre o comportamento de novilhos terminados em confinamento. Verificou-se efeito positivo no desempenho dos animais confinados sobre as características relacionadas ao ganho médio diário $(1,235 \mathrm{vs}$. $1,099 \mathrm{~kg} /$ dia $)$ e a conversão alimentar (7,22 vs. 7,95 kg de matéria seca ingerida para kg de ganho de peso), demonstrando a eficácia na utilização sobre o tratamento controle. A inclusão de leveduras vivas secas à dieta não gerou alterações nas características da carcaça, na qualidade da carne e nos componentes de rendimento da carcaça na produção de novilhos de corte superjovens.

Palavras-chave: Aditivos. Bovinos de corte. Conversão alimentar. Ganho de peso médio diário.

\section{Abstract}

The objective of this experiment was to evaluate the performance, meat and carcass characteristics of confined non-castrated young cattle finished with a diet composed by corn silage with and without Sacharomyces cerevisie (yeast culture) inclusion. Thirty-six steers had been used, where eighteen were 
Canchim (5/8 Charolais and 3/8 Nelore) and eighteen Brangus (1/2 Angus and 1/2 Nelore), with average age of 8 months and initial body weight of $250 \mathrm{~kg}$. The experimental design was completely randomized, composed of two treatments, with six replications, and each repetition was performed in a bay with three animals. The positive effect of the inclusion of living dried yeast on the performance of the animals had been reduced with the advance of the confinement period. Feed conversion rate ( $\mathrm{kg} \mathrm{DM} / \mathrm{kg} \mathrm{LWG)} \mathrm{and} \mathrm{daily}$ live weight gain (LWG) were improved with the inclusion of yeast to the diet in comparison to the control. The inclusion of living dried yeast to the diet did not cause any alteration to the carcass characteristics, meat quality and on the carcass performance components of super-young beef cattle.

Keywords: Additive. Beef cattle. Feed conversion. Daily weight gain.

\section{Introdução}

A crescente demanda por produção intensificada tem exigido esforços na elaboração de dietas que promovam melhores resultados sobre o desempenho e características de carcaça, especialmente em bovinos de corte em confinamento, na tentativa de atrelar desempenhos otimizados, diminuição nos custos de produção, maiores rendimentos de carcaça e melhoria sobre os aspectos qualitativos da carne. $\mathrm{O}$ uso de aditivos como as leveduras vivas $(S$. cerevisiae) tem despertado interesse na obtenção de resultados potencialmente favoráveis.

As leveduras vivas (S. cerevisiae) auxiliam na manutenção do pH ruminal via estímulo de bactérias utilizadoras de lactato e contribuem em constante suprimento de nutrientes para a população bacteriana no intestino, considerando que o $\mathrm{pH}$ ótimo para crescimento da $S$. cerevisiae está em aproximadamente 4,5 (ROSE, 1997). No rúmen, a faixa de $\mathrm{pH}$ entre 6.0 e 6.5 inibe crescimento das leveduras, porém, capacita e estimula as mesmas à produção de compostos e enzimas (CHAUCHEYRAS-DURAND; FONTY, 2001).

Segundo Tricarico (2005), diversos trabalhos de pesquisa mostram que o aumento da produtividade animal, seja de carne ou de leite, por meio do uso da S. cerevisiae é resultado da sua capacidade de estimular a multiplicação de bactérias ruminais anaeróbicas totais, bactérias celulolíticas e bactérias utilizadoras de ácido láctico no rúmen. Esse processo altera o metabolismo e melhora os processos de digestão da porção fibrosa da dieta. Para Newbold, Wallace e McIntosh (1996) e Dawson e Hopkins (1992), em relação ao processo ruminal, as leveduras têm a capacidade de promover maior estímulo das bactérias anaeróbicas totais e das bactérias celulolíticas na degradação da fibra; isso porque alguns tipos de bactérias apresentam melhor desempenho na presença de leveduras. Com esta resposta de otimização do meio ruminal, além do aumento do volume total de fibras digeridas no rúmen, é possível prever aumento na ingestão de matéria seca, maior ganho de peso, melhor conversão alimentar e menos problemas metabólicos (DAWSON, 2000; DOREAU; JOUANY, 1998).

A avaliação dos componentes não integrantes das partes do corpo do animal e das características da carne e da carcaça são muito importantes para o entendimento da relação do desempenho dos animais em diferentes manejos alimentares. Segundo Pacheco et al. (2005a), os componentes não integrantes da carcaça são importantes para o frigorífico por causa da receita gerada com a comercialização no atacado, ou no caso de gorduras, ossos, coração, rins e fígado, entre outros, pela agregação de valor na fabricação de embutidos e afins. De maneira geral, quanto maior o rendimento das partes não integrantes da carcaça, maior o lucro do frigorífico e menor a remuneração por animal abatido repassado ao produtor devido à redução do rendimento da carcaça quente e/ou fria. Cabe ressaltar, no entanto, que é importante o estudo dos componentes não integrantes da carcaça e das características da carne e carcaça, por estas estarem diretamente relacionadas ao rendimento de carcaça dos animais e às exigências nutricionais da categoria animal em questão (PACHECO et al., 2005b).

Além do desempenho animal e da eficiência produtiva, devem-se considerar as perdas de nutrientes e seu impacto para o meio ambiente. Segundo Baker (1999), de 2 a 12\% da energia consumida 
pelos ruminantes pode ser perdida na forma de metano, gás este produzido no ambiente ruminal durante o processo de fermentação dos carboidratos. Modificações na dieta ou sobre os níveis de ingestão exercem efeito sobre a produção de metano produzido pelo rúmen, sendo diversos os fatores que interferem, destacando principalmente a qualidade dos nutrientes e a manipulação da microflora ruminal.

Portanto, deve-se considerar um ponto de inflexão entre a eficiência produtiva e o impacto ambiental na execução das etapas relacionadas ao sistema produtivo de ruminantes. As perdas de metano estão diretamente relacionadas a um menor desempenho e podem contribuir de maneira negativa para alterações ambientais, principalmente sobre o aquecimento global, segundo Cotton e Pielke (1995).

Em estudo realizado por Signoretti et al. (1999), mostrou-se que o nível de fibra e/ou de energia na dieta alimentar de bovinos em fase de terminação podem alterar tanto os componentes não integrantes da carcaça como as características da carne e carcaça e, consequentemente, alterar a receita do frigorífico e do produtor, sem considerar a questão de qualidade de produto final ofertado aos consumidores de carne bovina.

Este trabalho teve por objetivo avaliar o consumo diário de matéria seca, o desempenho animal, as características da carne e carcaça e os componentes de rendimento de carcaça de novilhos terminados em confinamento utilizando dietas compostas à base de silagem de milho mais concentrado com inclusão ou não de leveduras vivas secas (S. cerevisiae).

\section{Materiais e métodos}

0 experimento foi conduzido nas instalações do Núcleo de Produção Animal (Nupran) do Setor de Ciências Agrárias e Ambientais da Universidade Estadual do Centro-Oeste (Unicentro), em Guarapuava (PR).

0 experimento teve duração de 210 dias, sendo 42 dias de adaptação dos animais às dietas e instalações experimentais e, sequencialmente, três períodos de avaliação de 56 dias. Os animais foram terminados em confinamento, sendo alimentados, na forma ad libitum, duas vezes ao dia, às $6 \mathrm{~h} 00$ e às $17 \mathrm{~h} 30$.

As dietas experimentais foram constituídas por silagem de milho com inclusão fixa diária de núcleo proteico na proporção de $4 \mathrm{~kg} / \mathrm{animal}$ associada à presença (8 g/animal/dia) ou ausência $(0 \mathrm{~g} / \mathrm{ani}$ $\mathrm{mal} / \mathrm{dia}$ ) de leveduras vivas secas (S. cerevisiae, cepa L11) na concentração $1 \times 10^{10} \mathrm{UFC} / \mathrm{g}$, Procreatin $7^{\circledR}$ (Lesaffre Seeds Additives). Na preparação dos concentrados, foram utilizados os seguintes alimentos: farelo de soja, casca de soja, radícula de cevada, grãos de milho moído, calcário calcítico, fosfato bicálcico, sal comum e núcleo vitamínico-mineral. As dietas, na matéria seca oferecida, apresentaram teores médios de $11,5 \%$ de proteína bruta, 2,3\% de extrato etéreo, $0,55 \%$ de $\mathrm{Ca}, 0,35 \%$ de $\mathrm{P}$ e $0,19 \%$ de $\mathrm{Na}$. A composição química da silagem dos concentrados e da levedura viva utilizados nas dietas experimentais é apresentada no Quadro 1.

O consumo voluntário dos alimentos foi registrado diariamente através da pesagem da quantidade oferecida e das sobras do dia anterior. 0 manejo alimentar constou primeiramente do fornecimento da silagem no cocho e sequencialmente do concentrado sobre esta, de tal maneira que as sobras do dia anterior referem-se ao volumoso. 0 ajuste no fornecimento da quantidade da silagem de milho foi realizado diariamente, considerando uma sobra de $3 \%$ da matéria seca oferecida em relação à consumida, ao passo que a quantidade de concentrado oferecida aos animais foi constante independente do nível de consumo do volumoso e do aumento de peso dos animais.

As instalações foram constituídas de 12 baias semicobertas para o confinamento dos animais, com uma área de $15 \mathrm{~m}^{2}$ cada baia $(2,5 \times 6,0 \mathrm{~m})$ para três animais, com um comedouro de concreto, medindo 2,30 m de comprimento, 0,60 m de largura e 0,35 m de altura, além de um bebedouro metálico, regulado por boia automática.

Foram utilizados 36 novilhos inteiros, sendo 18 animais Canchim (5/8 Charolês 3/8 Nelore) e 18 animais Brangus (1/2 Angus 1/2 Canchim), com idade média de 8 meses, peso vivo médio inicial de $250 \mathrm{~kg}$ com desvio padrão de 1,8 kg, vermifugados e equilibrados por peso e condição corporal para cada baia. Os animais foram pesados, após jejum de sólidos de 12 horas, no início e no fim do período experimental, com pesagens intermediárias a cada 56 dias. 
As variáveis avaliadas, nos três períodos de avaliação foram os consumos médios diários de matéria seca, expressos por kg/animal (CMSD) e por $100 \mathrm{~kg}$ de peso vivo (CMSP), o ganho de peso médio diário (GMD) e a conversão alimentar (CA).

Foram realizadas amostras compostas das silagens e dos concentrados de cada tratamento durante os períodos de avaliação do confinamento. As amostras das silagens e dos concentrados foram levadas à estufa com ventilação a $55^{\circ} \mathrm{C}$ por 72 horas para determinação da matéria parcialmente seca. As amostras pré-secas foram moídas em moinho tipo Wiley com peneira de $1 \mathrm{~mm}$ de diâmetro e conduzidas posteriormente para análise químico-bromatológica.

Nas amostras pré-secas das silagens e dos concentrados, foram estimados os teores de matéria seca (MS), matéria mineral (MM) e proteína bruta (PB), segundo técnicas descritas pela ASSOCIATION OF OFFICIAL ANALYTICAL CHEMISTS - AOAC (1995). Os teores de fibra em detergente neutro (FDN) foram obtidos conforme método de Van Soest, Robertson e Lewis, (1991) com a-amilase termoestável; e para calcular os teores de fibra em detergente ácido (FDA), seguiu-se o método de Goering e Van Soest (1970).

A análise do comportamento dos animais foi realizada em período contínuo de 72 horas, na fase final do confinamento, do segundo para o terceiro período de avaliação, com início às 12 horas no primeiro dia e término às 12 horas do quarto dia de avaliação. As observações foram realizadas por 12 observadores, durante 72 horas, em sistema de rodízio a cada 6 horas. As leituras foram tomadas em intervalos regulares de três minutos. Os dados do comportamento animal, representado pelas atividades de ócio, ruminação, consumo de água e consumo de alimento, foram expressos em horas/dia. Ainda foram observadas, seguindo a mesma metodologia, a frequência de cada atividade, expressa em número de vezes/dia.

Ao término do confinamento, obedecendo a um jejum de sólidos de 12 horas, os animais foram pesados antes do carregamento para o frigorífico, obtendo-se o peso de fazenda. Os abates seguiram o fluxo normal de um abatedouro. Após o abate, com a remoção da pele e evisceração dos 36 animais, as carcaças foram identificadas, lavadas, pesadas e resfriadas a $-2{ }^{\circ} \mathrm{C}$ por 24 horas. Decorrido esse tempo, as carcaças foram novamente pesadas, obtendo-se o peso de carcaça fria e a estimação das perdas no resfriamento. Realizou-se, em seguida, a avaliação subjetiva sugerida por Muller (1987). Por esse método, avaliam-se conformação - em uma escala de 1 a 18 pontos, em que escores mais altos indicam melhor conformação -, e maturidade fisiológica das carcaças - em uma escala de 1 a 15 pontos, em que a maior pontuação indica menor grau de maturidade.

Nas carcaças também foram mensuradas cinco medidas de desenvolvimento: (1) comprimento de carcaça - distância entre o bordo cranial medial do osso púbis e o bordo cranial medial da primeira costela; (2) comprimento de perna - distância entre a borda cranial medial do osso púbis e a articulação tibiotarsiana; (3) comprimento de braço - distância entre a tuberosidade do olecrano e a articulação radiocarpiana; (4) perímetro de braço - obtido na região mediana do braço circundando com uma fita métrica; e (5) espessura do coxão - medida com compasso, perpendicularmente ao comprimento de carcaça, tomando-se a maior distância entre o corte que separa as duas meias carcaças e os músculos laterais da coxa, conforme as metodologias sugeridas por Muller (1987).

Após realização dessas medidas, realizou-se um corte perpendicular no músculo longissimus dorsi, na altura da $12^{\underline{a}}$ costela. Foram avaliadas as características subjetivas de: (1) cor - em escala de 1 a 5 pontos, em que um valor menor indica coloração mais escura; (2) textura - em escala de 1 a 5 pontos, em que um valor menor indica textura muito grosseira; (3) marmoreio - em escala de 1 a 18 pontos, onde um valor maior indica marmoreio mais abundante; e (4) espessura de gordura (MULLER, 1987). Para determinar a porcentagem de cortes comerciais, dividiu-se a meia carcaça esquerda em dianteiro, traseiro e costilhar e, por pesagem, calculou-se a porcentagem destes em relação à meia carcaça.

No momento do abate, realizou-se a caracterização das partes do corpo não integrantes da carcaça dos novilhos abatidos por meio de coleta dos pesos dos seguintes componentes: cabeça, língua, cauda, patas e pele (denominados componentes externos); coração, rins, fígado, baço e pulmões (denominados órgãos vitais); diafragma, rúmen-retículo cheio, rúmen-retículo vazio, abomaso cheio, abomaso vazio, intestinos delgado e grosso cheios. 
0 delineamento experimental foi o inteiramente casualizado, composto por dois tratamentos, com seis repetições, sendo cada repetição em baia com três animais. Os dados coletados para cada variável foram submetidos à análise de variância com comparação das médias, a 5\% de significância, com uso do programa estatístico SAS INSTITUTE (1993).

\section{Resultados e discussão}

No Quadro 1, constam os resultados das análises químicas dos alimentos utilizados nas dietas experimentais.

A participação percentual do volumoso (silagem de milho) variou, com base na matéria seca, conforme o período de avaliação do confinamento. Para o tratamento com inclusão de levedura, a silagem obteve participação ao longo dos três períodos de $68,86 \%$, não sendo diferente estatisticamente do tratamento sem inclusão de levedura, cuja participação da silagem de milho foi de $70,1 \%$ na média dos períodos.

Foi observado aumento linear na participação do volumoso nas dietas experimentais ao longo dos períodos nos tratamentos com e sem Saccharomyces cerevisiae. Esse efeito observado está atrelado ao aumento do consumo de matéria seca ao longo dos períodos experimentais, pois os níveis de inclusão da fração concentrada foram fixos em $4 \mathrm{~kg} /$ dia para ambos os tratamentos com ou sem levedura.

No Quadro 2 estão apresentados os valores médios de consumo de matéria seca por animal/dia (CMSD) e por $100 \mathrm{~kg}$ de peso vivo (CMSP), ganho de peso diário (GMD) e conversão alimentar (CA), em função das dietas com presença ou ausência de leveduras. Não houve interação entre uso de leveduras e período de confinamento.

Os dados apresentados no Quadro 3 mostram que o CMSD e o CMSP manifestaram comportamento linear ao período de terminação dos animais, independente do uso de leveduras na dieta. Com o avanço do confinamento, no período de 168 dias de confinamento os animais diariamente aumentaram o CMSD em 0,0144 kg e reduziram o CMSP em $0,0037 \%$. Tal fato justifica-se pela redução gradativa da participação da fração concentrada na relação volumoso: concentrado com o avanço do período de terminação dos animais, como pode ser observado no Quadro 2. Na média geral, o uso de leveduras não afetou ( $\mathrm{p}<0,05$ ) os CMSD e CMSP, apresentando valores médios de $8,76 \mathrm{~kg} /$ dia e $2,32 \%$ do peso vivo, respectivamente.

Segundo Desnoyers et al. (2009), em certas condições, as leveduras têm mostrado eficácia sobre a atividade de degradação da fibra e sobre o crescimento dos microorganismos ruminais, sendo esse efeito explicado pelo aumento da capacidade de extração do $\mathrm{O}_{2}$ no ambiente ruminal pelas células de leveduras.

Um comportamento linear decrescente de 0,0021 $\mathrm{kg} /$ dia foi observado no GMD com o avanço do período de confinamento dos animais, independente do uso de leveduras. Já na análise da CA, verificou-se comportamento linear crescente de $0,0249 \mathrm{~kg}$ de matéria seca consumida para cada quilo de ganho de peso para cada dia de avanço do período de confinamento dos animais, independente da presença ou ausência da leveduras à dieta.

Na média geral dos períodos, animais suplementados com leveduras obtiveram maior $(\mathrm{p}<0,05)$

Quadro 1 - Composição químico-bromatológica da silagem de milho, concentrado e levedura com base na matéria seca total

\begin{tabular}{lllllllll}
\hline Constituintes & MS & MO & PB & EE & FDN & FDA & Ca & P \\
\cline { 2 - 9 } & \% & & \multicolumn{7}{c}{ \% na MS } \\
\hline Silagem de milho & 32,24 & 97,82 & 6,79 & 2,39 & 43,66 & 25,71 & 0,28 & 0,16 \\
Concentrado & 89,17 & 94,82 & 15,39 & 2,82 & 25,36 & 6,79 & 0,80 & 0,40 \\
Levedura viva seca & 97,70 & 99,23 & 42,10 & - & - & - & - & - \\
\hline
\end{tabular}

Legenda: $\mathrm{MS}$ = matéria seca; $\mathrm{MO}$ = matéria orgânica; $\mathrm{PB}$ = proteína bruta; $\mathrm{EE}$ = extrato etéreo; FDN = fibra em detergente neutro; FDA = fibra em detergente ácido; $\mathrm{Ca}=$ cálcio; $\mathrm{P}=$ fósforo.

Fonte: Dados da pesquisa. 
GMD (1,235 vs. $1,099 \mathrm{~kg} /$ dia) e melhor $(\mathrm{p}<0,05)$ CA $(7,22$ vs. 7,95 kg de matéria seca ingerida para quilo de ganho de peso) comparativamente ao tratamento controle, respectivamente. Esses valores são superiores aos encontrados por Gattass et al. (2008), que trabalharam com animais $1 / 2$ Red Angus e $1 / 2$ Nelore, e obtiveram um GMD de $1,160 \mathrm{~kg} /$ dia para o tratamento com inclusão e 1,218 kg/dia para o tratamento controle, com participação de concentrado: volumoso de 50:50. Porém, esses resultados discordam dos obtidos por Erasmus et al. (2009), que, ao realizarem meta-análise de 15 ensaios experimentais, observaram um GMD de $1,57 \mathrm{~kg} / \mathrm{dia}$ quando houve inclusão de levedura.
Kuss et al. (2009) também obtiveram resultados mais satisfatórios em relação ao GMD, com valores de $1,47 \mathrm{~kg} /$ dia para o tratamento com inclusão de Sacharomyces cerevisiae em animais oriundos de cruzamentos industriais e com dieta apresentando relação volumoso-concentrado de 52:48. Esses resultados mais satisfatórios podem ser justificados, segundo Van Soest (1994), pelo fato de o aumento da participação da fração concentrado culminar em maior eficiência quando há inclusão de leveduras; isso pode estar relacionado ao controle do $\mathrm{pH}$ e na dosagem utilizada.

0 incremento de $12,4 \%$ sobre o GMD e a melhoria de $9,2 \%$ sobre a CA são superiores aos

Quadro 2 - Consumo diário de matéria seca por animal (CMSD) e por $100 \mathrm{~kg}$ de peso vivo (CMSP), ganho médio diário (GMD) e conversão alimentar (CA), de novilhos terminados em confinamento com dietas na presença ou ausência de leveduras

\begin{tabular}{|c|c|c|c|c|}
\hline \multirow[t]{2}{*}{ Tratamentos } & \multicolumn{3}{|c|}{ Períodos da terminação } & \multirow[t]{2}{*}{ Média } \\
\hline & 09/06 a 03/08 & $04 / 08$ a $28 / 09$ & $29 / 09$ a $24 / 11$ & \\
\hline & \multicolumn{3}{|c|}{ CMSD, kg/dia } & \\
\hline Com leveduras & 7,77 & 9,07 & 9,36 & $8,74 \mathrm{a}$ \\
\hline Sem leveduras & 7,82 & 9,13 & 9,42 & $8,79 a$ \\
\hline Média & $7,79 \mathrm{~b}$ & $9,10 \mathrm{a}$ & 9,40 a & \\
\hline \multicolumn{4}{|c|}{ Equação geral de regressão: CMSD = 7,1581 + 0,0144D ( $\left(R^{2}: 0,5123 ; C V: 7,52 \% ; p<0,0001\right)$} & \\
\hline & \multicolumn{3}{|c|}{ CMSP, \% peso vivo } & \\
\hline Com leveduras & 2,51 & 2,36 & 2,08 & $2,31 \mathrm{a}$ \\
\hline Sem leveduras & 2,52 & 2,37 & 2,10 & $2,33 \mathrm{a}$ \\
\hline Média & $2,51 \mathrm{a}$ & $2,36 \mathrm{~b}$ & $2,09 c$ & \\
\hline \multicolumn{4}{|c|}{ Equação geral de regressão: CMSP = 2,7422 - 0,0037D ( $\left(R^{2}: 0,6672 ; C V: 5,36 \% ; p<0,0001\right)$} & \\
\hline & \multicolumn{3}{|c|}{ GMD, kg/dia } & \\
\hline Com leveduras & 1,313 & 1,216 & 1,174 & $1,235 \mathrm{a}$ \\
\hline Sem leveduras & 1,215 & 1,209 & 0,874 & $1,099 \mathrm{~b}$ \\
\hline Média & 1,264 a & 1,213 a & $1,023 b$ & \\
\hline \multicolumn{4}{|c|}{ Equação geral regressão: GMD = 1,4074 - 0,0021D ( $\left.R^{2}: 0,29939 ; C V: 13,25 \% ; p<0,006\right)$} & \\
\hline & \multicolumn{3}{|c|}{ CA, (CMSD/GMD) } & \\
\hline Com leveduras & 5,97 & 7,56 & 8,14 & $7,22 \mathrm{~b}$ \\
\hline Sem leveduras & 6,44 & 7,56 & 9,86 & $7,95 \mathrm{a}$ \\
\hline Média & 6,21 c & $7,56 \mathrm{~b}$ & $8,99 \mathrm{a}$ & \\
\hline \multicolumn{4}{|c|}{ Equação regressão: $C A=4,7997$ + 0,0249D ( $\left.R^{2}: 0,6139 ; C V: 12,24 \% ; p<0,0001\right)$} & \\
\hline
\end{tabular}

Legenda: $C M S D$ = consumo diário de matéria seca por animal; $C M S P=$ consumo diário de matéria seca por $100 \mathrm{~kg}$ de peso vivo; $\mathrm{GMD}=$ ganho médio diário; $C A=$ conversão alimentar (de novilhos terminados em confinamento com dietas na presença ou ausência de leveduras); * $\mathrm{D}$ = período de confinamento variando de 1 a 168 dias.

Fonte: Dados da pesquisa.

Nota: Médias, na coluna, seguidas por letras minúsculas diferentes diferem $(\mathrm{p}<0,05)$ pelo Teste $\mathrm{F}$. 
reportados por Pascoal et al. (2000), sendo encontrados valores na ordem de 4,5\% e 7,0\% para o GMD e CA, respectivamente. É possível que os resultados obtidos sobre o GMD e CA tenham sido motivados pelo comportamento ingestivo, mas não foram verificadas diferenças $(\mathrm{p}>0,05)$ sobre as variáveis relacionadas ao comportamento animal. 0 que se observou, apenas, foi o maior número de vezes que os animais do tratamento com inclusão de leveduras realizaram o consumo de alimentos, 22,5 vezes, contra 20,3 vezes do tratamento controle, estando intimamente ligado à digestibilidade e à taxa de passagens dos nutrientes (Quadro 3).

Observa-se no Quadro 4 que não houve diferença significativa para o peso de abate, peso de carcaça quente, rendimento de carcaça, perdas por resfriamento, porcentagem de serrote, costilhar e dianteiro.

Os valores reportados por Pacheco et al. (2005a), Kuss et al. (2009) e Beauchemin et al. (1997) para as categorias de bovinos jovem e superjovem acompanharam as médias registradas neste estudo, evidenciando não haver benefícios da adição de levedura sobre essas variáveis.

A carcaça de ambos os tratamentos se mantiveram dentro da faixa de exigência definida pelos frigoríficos (3 a $6 \mathrm{~mm}$ ). A menor proteção das carcaças dos animais suplementados com leveduras em razão da menor espessura de gordura subcutânea e de menor marmoreio determinou queda mais acentuada na temperatura no resfriamento das carcaças, fator negativo sob aspectos relacionados à maciez, cor e textura da carne, ou ainda relativo às perdas de resfriamento, sem observar diferenças estatísticas $(p>0,05)$ para esses parâmetros (Quadro 4).

Não houve diferença $(\mathrm{p}>0,05)$ na inclusão de levedura para textura, coloração, marmoreio e maturidade da carne e conformação da carcaça, apresentando valores médios de 3,43 pontos (textura fina a levemente grosseira), 3,74 (4,0; vermelha), 3,48 (leve inferior), 14,2 pontos (indicação de idade inferior a 15 meses) e 8,4 pontos (regular típica a regular superior), respectivamente (Quadro 4).

Não foi confirmada diferença $(\mathrm{p}>0,05)$ entre a inclusão de $S$. cerevisiae e o tratamento controle para os dados de comprimento da carcaça, comprimento da perna, espessura do coxão, comprimento do braço e perímetro do braço de novilhos terminados em confinamento. Beauchemin et al. (1997) e Kuss et al. (2009) também não relataram diferenças sobre o efeito da inclusão de $S$. cerevisiae com relação às variáveis de carcaça em novilhos terminados em confinamento.

Quadro 3 - Comportamento animal, expresso em horas despendidas ao dia por novilhos terminados em confinamento com dietas na presença ou ausência de leveduras

\begin{tabular}{|c|c|c|c|c|c|}
\hline \multirow[b]{2}{*}{ Variáveis } & \multicolumn{2}{|c|}{ Tratamentos } & \multirow[b]{2}{*}{ Média } & \multirow[b]{2}{*}{ CV (\%) } & \multirow[b]{2}{*}{ Probabilidade } \\
\hline & Com Levedura & Sem levedura & & & \\
\hline & \multicolumn{2}{|c|}{ horas/dia-1 } & & & \\
\hline Ruminação & $7,77 a$ & $7,97 a$ & 7,87 & 14,13 & 0,7656 \\
\hline Ócio & $12,30 \mathrm{a}$ & $12,06 \mathrm{a}$ & 12,18 & 11,53 & 0,7687 \\
\hline Consumo de alimentos & $3,68 \mathrm{a}$ & $3,72 \mathrm{a}$ & 3,70 & 14,06 & 0,8925 \\
\hline \multirow[t]{2}{*}{ Consumo de água } & $0,25 a$ & $0,25 \mathrm{a}$ & 0,25 & 47,35 & 0,9057 \\
\hline & \multicolumn{2}{|c|}{ número de vezes/dia } & & & \\
\hline Alimentação & $22,5 \mathrm{a}$ & $20,3 a$ & 21,4 & 15,37 & 0,3028 \\
\hline Consumo de água & $6,8 \mathrm{a}$ & $6,4 \mathrm{a}$ & 6,6 & 28,45 & 0,7266 \\
\hline Excreções Líquidas & $5,4 \mathrm{a}$ & $5,4 \mathrm{a}$ & 5,4 & 18,33 & 0,9989 \\
\hline Excreções Sólidas & $5,5 \mathrm{a}$ & $5,1 \mathrm{a}$ & 5,3 & 22,73 & 0,6227 \\
\hline
\end{tabular}

Fonte: Dados da pesquisa.

Nota: Médias, na linha, seguidas por letras minúsculas diferentes diferem $(p<0,05)$ pelo Teste $F$. 
Quadro 4 - Peso de abate, peso de carcaça quente e peso de carcaça fria, rendimento de carcaça, perdas no resfriamento e constituição da carcaça em percentagem de novilhos terminados em confinamento com dietas na presença ou ausência de leveduras

\begin{tabular}{|c|c|c|c|c|c|}
\hline \multirow[t]{2}{*}{ Variáveis } & \multicolumn{2}{|c|}{ Tratamentos } & \multirow[t]{2}{*}{ Média } & \multirow[t]{2}{*}{$\mathrm{CV}, \%$} & \multirow[t]{2}{*}{ Probabilidade } \\
\hline & Com Levedura & Sem levedura & & & \\
\hline Peso vivo de fazenda (kg) & $483,1 \mathrm{a}$ & $469,7 a$ & 476,4 & 5,25 & 0,3767 \\
\hline Peso de carcaça quente $(\mathrm{kg})$ & $265,1 \mathrm{a}$ & $260,3 \mathrm{a}$ & 262,7 & 4,88 & 0,5314 \\
\hline Rendimento de carcaça (\%) & 54,87 a & $55,43 a$ & 55,15 & 2,44 & 0,4379 \\
\hline Perdas no resfriamento de carcaça (\%) & $1,35 \mathrm{a}$ & $1,58 \mathrm{a}$ & 1,46 & 15,62 & 0,1071 \\
\hline Porcentagem de serrote (\%) & $50,19 a$ & $50,24 \mathrm{a}$ & 50,21 & 2,77 & 0,9500 \\
\hline Porcentagem de costilhar (\%) & $14,20 \mathrm{a}$ & $14,60 \mathrm{a}$ & 14,40 & 5,21 & 0,3719 \\
\hline Porcentagem de dianteiro (\%) & 35,62 a & $35,16 \mathrm{a}$ & 35,39 & 4,37 & 0,6193 \\
\hline Espessura de gordura (mm) & $3,21 \mathrm{a}$ & $3,42 \mathrm{a}$ & 3,31 & 23,93 & 0,6587 \\
\hline Textura da carne (pontos) & $3,51 \mathrm{a}$ & $3,36 \mathrm{a}$ & 3,43 & 9,82 & 0,4738 \\
\hline Cor da carne (pontos) & 3,96 a & 3,52 a & 3,74 & 8,04 & 0,0790 \\
\hline Marmoreio (pontos) & 3,33 a & 3,63 a & 3,48 & 22,23 & 0,5196 \\
\hline Maturidade da carcaça (pontos) & $14,17 \mathrm{a}$ & $14,22 \mathrm{a}$ & 14,19 & 2,86 & 0,8140 \\
\hline Conformação da carcaça (pontos) & $8,56 \mathrm{a}$ & $8,28 \mathrm{a}$ & 8,42 & 8,12 & 0,4968 \\
\hline Temperatura da carcaça resfriada $\left({ }^{\circ} \mathrm{C}\right)$ & $13,59 \mathrm{a}$ & $13,82 \mathrm{a}$ & 13,71 & 8,55 & 0,7355 \\
\hline Comprimento da carcaça (cm) & 124,81 a & 125,28 a & 125,04 & 1,91 & 0,7383 \\
\hline Comprimento de perna (cm) & 77,88 a & 79,14 a & 78,51 & 2,32 & 0,2561 \\
\hline Espessura de coxão (cm) & $24,49 a$ & $24,75 \mathrm{a}$ & 24,62 & 6,39 & 0,7778 \\
\hline Comprimento de braço $(\mathrm{cm})$ & $39,42 \mathrm{a}$ & $39,92 \mathrm{a}$ & 39,67 & 2,68 & 0,4342 \\
\hline
\end{tabular}

Fonte: Dados da pesquisa.

Nota: Médias, na linha, seguidas por letras minúsculas diferentes diferem $(\mathrm{p}<0,05)$ pelo Teste $\mathrm{F}$.

De maneira geral, os dados do Quadro 5 mostram que não houve $(\mathrm{p}>0,05)$ alterações nos pesos de cabeça com língua, cauda, coração, fígado, rins, pulmões, retículo-rúmen cheio, retículo-rúmen vazio, abomaso cheio, intestinos cheios e pele de novilhos em função da presença ou ausência de leveduras, apresentando valores médios (em quilogramas - kg) de $13,3,0,95,1,60,4,52,0,79,7,02,35,3,8,2,7,8,18,79$ e 43 , respectivamente.

Resultados similares são descritos nos estudos com animais em crescimento até 24 meses utilizando leveduras na composição das dietas (JESSÉ et al., 1976; JORGE; FONTES, 2001; RESTLE et al., 2005).

0 procedimento de abate foi idêntico para todos os animais, visto que o tempo de jejum a que os animais são submetidos no pré-abate pode afetar o rendimento de carcaça (FATURI et al., 2002).

Com base nos dados apresentados e discutidos, sugere-se que a adição de leveduras na quantidade de $8 \mathrm{~g} /$ animal/dia de $S$. cerevisiae tenha proporcionado alterações positivas sobre a saúde e dinâmica do ambiente ruminal e consequentemente sobre a digestibilidade dos nutrientes, mesmo em dietas com alta proporção de volumoso. Isso promoveu resultados satisfatórios sobre a CA e GMD, porém não alterou as características da carcaça, a qualidade da carne e os componentes de rendimento de carcaça na produção de novilhos de corte superjovens.

\section{Conclusões}

A adição de leveduras de $S$. cerevisiae vivas na quantidade de $8 \mathrm{~g} / \mathrm{animal} / \mathrm{dia}$ resultou, mesmo perante dietas com alta proporção de volumoso, em melhorias no ganho de peso diário e na conversão alimentar de novilhos de corte terminados em confinamento. 
Quadro 5 - Pesos médios de cabeça com língua, cauda, coração, fígado, rins, pulmões, retículo-rúmen cheio, retículo-rúmen vazio, abomaso cheio, intestinos cheios e pele de novilhos terminados em confinamento com dietas com e sem leveduras

\begin{tabular}{lccccc}
\cline { 1 - 3 } Variáveis & \multicolumn{2}{c}{ Tratamentos } & Média & CV (\%) & Probabilidade \\
\cline { 1 - 3 } Peso (kg) & Com Levedura & Sem levedura & & & \\
\cline { 1 - 3 } Cabeça & $12,43 \mathrm{a}$ & $12,56 \mathrm{a}$ & 12,49 & 6,63 & 0,7863 \\
Língua & $0,85 \mathrm{a}$ & $0,81 \mathrm{a}$ & 0,83 & 7,31 & 0,2622 \\
Cauda & $0,92 \mathrm{a}$ & $0,98 \mathrm{a}$ & 0,95 & 8,63 & 0,3002 \\
Diafragma & $2,36 \mathrm{a}$ & $2,40 \mathrm{a}$ & 2,38 & 10,99 & 0,8216 \\
Patas & $9,61 \mathrm{a}$ & $9,51 \mathrm{a}$ & 9,56 & 5,73 & 0,7582 \\
Coração & $1,64 \mathrm{a}$ & $1,57 \mathrm{a}$ & 1,60 & 9,06 & 0,4137 \\
Fígado & $4,49 \mathrm{a}$ & $4,56 \mathrm{a}$ & 4,52 & 7,44 & 0,7142 \\
Rins & $0,81 \mathrm{a}$ & $0,78 \mathrm{a}$ & 0,79 & 3,62 & 0,0858 \\
Baço & $1,55 \mathrm{a}$ & $1,62 \mathrm{a}$ & 1,59 & 18,61 & 0,6969 \\
Pulmões & $6,86 \mathrm{a}$ & $7,17 \mathrm{a}$ & 7,02 & 5,69 & 0,2066 \\
Retículo-rúmen cheio & $34,82 \mathrm{a}$ & $35,77 \mathrm{a}$ & 35,29 & 12,39 & 0,7160 \\
Retículo-rúmen vazio & $8,19 \mathrm{a}$ & $8,20 \mathrm{a}$ & 8,19 & 7,61 & 0,9820 \\
Abomaso cheio & $8,00 \mathrm{a}$ & $7,65 \mathrm{a}$ & 7,83 & 10,88 & 0,4949 \\
Intestinos cheios & $18,91 \mathrm{a}$ & $18,66 \mathrm{a}$ & 18,78 & 9,86 & 0,8235 \\
Pele & $43,19 \mathrm{a}$ & $44,21 \mathrm{a}$ & 43,00 & 7,55 & 0,6062 \\
\hline
\end{tabular}

Fonte: Dados da pesquisa.

Nota: Médias, na linha, seguidas por letras minúsculas diferentes diferem $(p<0,05)$ pelo Teste Tukey.

O uso de leveduras não altera as características da carcaça, qualidade da carne e dos componentes de rendimento de carcaça na produção de novilhos de corte superjovens em confinamento.

\section{Referências}

ASSOCIATION OF OFFICIAL ANALYTICAL CHEMISTS AOAC. Official methods of analysis. 16th. ed. Washington, DC: AOAC, 1995.

BAKER, S. K. Rumenmethanogens, and inhibition of methanogenesis. Australian Journal of Agricultural Research, v. 50, n. 8, p. 1293-1298, 1999. doi:10.1071/ AR99005.

BEAUCHEMIN, et al. Effects of fibrolytic enzymes in corn or barley diets on performance and carcass characteristics of feedlot cattle. Canadian Journal of Animal Science, v. 77, n. 4, p. 645-653, 1997. doi:10.4141/A97-050.
CHAUCHEYRAS-DURAND, F; FONTY, G. Establishment of cellulolytic bacteria and development of gnotobiotically-reared lambs receiving the microbial additive Saccharomyces cerevisiae CNCM-1077. Reproduction and Nutritional Developed, v. 41, n. 1, p. 57-68, 2001. doi:10.1051/ rnd:2001112.

COTTON, W. R.; PIELKE, R. A. Human impacts on weather and climate. Cambridge: Cambridge University Press, 1995.

DAWSON, K. A.; HOPKINS, D. M. Differential effects of live yeast culture in animal production: a review of research over the last six years. Supplement to the Proceedings of Alltech's 8th. Annual Symposium. Nicholasville: Alltech Technical Publications, 1992.

DAWSON, K. A. Some milestones in our understanding of yeast culture supplementation in ruminants and their implications in animal production systems. In: LYONS, T. P.; JACQUES, K. A. (Ed.). Supplement to the Proceedings of Alltech's 16th. Annual Symposium. Nottingham: Nottingham University Press, 2000. p. 473-486. 
DESNOYERS, M. et al. Meta-analysis of the influence of Sacharomyces cerevisiae supplementation on ruminal parameters and Milk production of ruminants. Journal of Dairy Science, v. 92, n. 4, p. 1620-1632, 2009. doi:10.3168/jds.2008-1414.

DOREAU, M.; JOUANY, J. P. Effect of a Saccharomyces cerevisae culture on nutrient digestion in lactating dairy cows. Journal Dairy Science, v. 81, n. 12, p. 3214-3221, 1998. doi:10.3168/jds.S0022-0302(98)75885-0.

ERASMUS, L. J. et al. A meta-analysis of the effect of monensin or live yeast or a combination thereof on performance of the beef cattle. Journal of Animal Science, v. 87 , suppl. 2, p. 281, 2009.

FATURI, C. et al. Características da carcaça e da carne de novilhos de diferentes grupos genéticos alimentados em confinamento com diferentes proporções de grão de aveia e grão de sorgo no concentrado. Revista Brasileira de Zootecnia, v. 31, n. 5, p. 2024-2035, 2002. doi:10.1590/ S1516-35982002000800018.

GATTASS, C. B. A. et al. Consumo, digestibilidade aparente e ganho de peso em bovinos de corte confinados e suplementados com cultura de levedura (Saccharomyces cerevisiae cepa 1026). Ciência Animal Brasileira, v. 9, n. 3, p. $535-542,2008$

GOERING, H. K.; VAN SOEST, P. J. Forage fiber analysis: apparatus reagents, procedures and some applications. Washington, DC: [s. n.], 1970.

JESSÉ, W. G. et al. Effects of ration energy and slaughter weight on composition of empty body and carcass gain of beef cattle. Journal of Animal Science, v. 43, n. 2, p. $418-425,1976$.

JORGE, A. M.; FONTES, C. A. A. Desenvolvimento relativo das partes do corpo de zebuínos de quatro raças. Ciência Rural, v. 31, n. 5, p. 857-861, 2001. doi:10.1590/ S0103-84782001000500019.

KUSS, F. et al. Desempenho e características da carcaça e da carne de novilhos não-castrados alimentados com ou sem adição de monensina e/ou probiótico à dieta. Ciência Animal Brasileira, v. 39, n. 4, p. 1180-1186, 2009.

MULLER, L. Normas para avaliação de carcaças e concurso de carcaça de novilhos. 2. ed. Santa Maria: UFSM, 1987.
NEWBOLD, C. J.; WALLACE, R. J.; McINTOSH, F. M. Mode of action of yeast Saccharomyces cerevisae as a feed additive for ruminates. Bristish Journal of Nutrition, v. 76, n. 2, p. 249-261, 1996. doi:10.1079/BJN19960029.

PACHECO, P. S. et al. Características das partes do corpo não-integrantes da carcaça de novilhos jovens e superjovens de diferentes grupos genéticos. Revista Brasileira de Zootecnia, v. 34, n. 5, p. 1678-1690, 2005a. doi:10.1590/S1516-35982005000500029.

PACHECO, P. S. et al. Características quantitativas de carcaça de novilhos jovens e superjovens de diferentes grupos genéticos. Revista Brasileira de Zootecnia, v. 34, n. 5, p. 1666-1677, 2005b. doi:10.1590/ S1516-35982005000500030.

PASCOAL, L. L. et al. Uso de ionóforos e minerais no confinamento e em pastagem cultivada. In: RESTLE, J. Eficiência na produção de bovinos de corte. Santa Maria: UFSM, 2000. p. 304-332.

RESTLE, J. et al. Características das partes não-integrantes da carcaça de novilhos 5/8Nelore 3/8Charolês abatidos em três estádios de desenvolvimento. Revista Brasileira de Zootecnia, v. 34, n. 4, p. 1339-1348, 2005. doi:10.1590/S1516-35982005000400031.

ROSE, A. H. Yeast, a microorganism for all species: a theoretical look at its mode of action. In: LYONS, T. P. (Ed.). Biotechnology in the feed industry. Nicholasville: Alltech Technical Publications, 1997. p. 113-118.

SAS INSTITUTE. SAS/STAT user's Guide: statistics, version 6. 4th. ed. North Caroline: SAS Institute Inc., 1993. v. 2.

SIGNORETTI, R. D. et al. Características das partes não-integrantes da carcaça animal e desenvolvimento do tratointestinal de bezerros da raça Holandesa alimentados com dietas contendo quatro níveis de concentrado. Revista Brasileira de Zootecnia, v. 28, n. 4, p. 875-882, 1999. doi:10.1590/S1516-35981999000400031.

TRICARICO, J. M. Otimizando a função ruminal: benefícios de Beef-Sacc na produtividade animal. In: SIMPÓSIO BRASILEIRO DA INDÚSTRIA DE ALIMENTAÇÃO ANIMAL, 2.; CRIAR, INOVAR E ELEVAR - BIOTECNOLOGIA NUTRICIONAL DA INDÚSTRIA DE ALIMENTAÇÃO ANIMAL, 2005, Curitiba. Anais... Curitiba: Simpósio Brasileiro Alltech, 2005. p. 119-126. 
VAN SOEST, P. J.; ROBERTSON, J. B.; LEWIS, B. A. Symposium: Carbohydrate methodology, metabolism, and nutritional implications in dairy cattle. Methods for dietary fiber, neutral detergent fiber, and nonstarch polysaccharides in relation to animal nutrition. Journal of Dairy Science, v. 74, n. 10, p. 3583-3597, 1991. doi:10.3168/jds. S0022-0302(91)78551-2.

VAN SOEST, P. J. Nutrition ecology of the ruminant. New York: Cornell University, 1994.

Recebido: 07/08/2012

Received: 08/07/2012

Aprovado: 18/02/2013

Approved: 02/18/2013 